\title{
ARTICLE \\ A Constitutive Modeling and Experimental Effect of Shock Wave on the Microstructural Sub-strengthening of Granular Copper
}

\author{
A. D. Sharma ${ }^{1^{*}}$ A. K. Sharma ${ }^{2}$ N. Thakur ${ }^{3}$ \\ 1. Department of Physics, Government College Chowari, Chamba, 176302, India \\ 2. Om Sterling Global University- Hisar, Haryana, 125001, India \\ 3. Department of Physics, Himachal Pradesh University, Shimla, 171005, India
}

\begin{tabular}{l} 
ARTICLE INFO \\
\hline Article history \\
Received: 25 August 2021 \\
Accepted: 27 August 2021 \\
Published Online: 30 August 2021 \\
\hline
\end{tabular}

\section{Keywords:}

Shock waves

Wide angle $\mathrm{x}$-ray diffraction

Microstructure

FE-SEM

Laser diffraction

Microhardness

\begin{abstract}
Micro-sized copper powder $(99.95 \%$; $\leq \leq 0.3$ ) has been shock-processed with explosives of high detonation velocities of the order of $7.5 \mathrm{~km} / \mathrm{s}$ to observe the structural and microstructural sub-strengthening. Axisymmetric shock-consolidation technique has been used to obtain conglomerates of granular $\mathrm{Cu}$. The technique involves the cylindrical compaction system wherein the explosive-charge is in direct proximity with the powder whereas the other uses indirect shock pressure with die-plunger geometry. Numeric simulations have been performed on with Eulerian code dynamics. The simulated results show a good agreement with the experimental observation of detonation parameters like detonation velocity, pressure, particle velocity and shock pressure in the reactive media. A pin contactor method has been utilized to calculate the detonation pressure experimentally. Wide angled $\mathrm{x}$-ray diffraction studies reveal that the crystalline structure (FCC) of the shocked specimen matches with the un-shocked specimen. Field emissive scanning electron microscopic examination of the compacted specimens show a good sub-structural strengthening and complement the theoretical considerations. Laser diffraction based particle size analyzer also points towards the reduced particle size of the shock-processed specimen under high detonation velocities. Micro-hardness tests conducted under variable loads of $0.1 \mathrm{~kg}, 0.05 \mathrm{~kg}$ and $0.025 \mathrm{~kg}$ force with diamond indenter optical micrographs indicate a high order of micro-hardness of the order of $159 \mathrm{H}_{\mathrm{v}}$. Nitrogen pycnometry used for the density measurement of the compacts shows that a compacted density of the order of $99.3 \%$ theoretical mean density has been achieved.
\end{abstract}

resistance make non-magnetic copper components a premier choice in the aerospace industries ${ }^{[1-5]}$. The solidification of commercially available or chemically/physically synthesized $\mathrm{Cu}$ powder involves hydraulic or isostatic processing, metal injection molding or sintering. Distinctive challenges arising on the solidification/ compaction of powders are due to deterioration of fine grained structure as well as formation

*Corresponding Author:

A. D. Sharma,

Department of Physics, Government College Chowari, Chamba, 176302, India;

Email:ads.hpu@gmail.com 
of undesired phases in the crystal structure that may result into weak sub-structural strengthening and poor mechanical properties. These powder metallurgical processes due to the high capital investment and extended operating period do not provide satisfactory microstructural sub-strengthening ${ }^{[-9-9]}$.

Rapid solidification by explosives is gaining a particular importance in the field of materials science and powder metallurgy wherein the destructive force is channelized for constructive roles. Explosives have number of novel applications in agriculture, forestry, civil engineering, drilling, cutting, welding, cladding and forming of metals, powder metallurgy and manufacturing industries in high temperature and pressure regime. The explosively generated shock wave compaction is quite advantageous due to its controlled detonation pressure that directly transmits shock waves to the powdered materials. Compaction of materials by shock waves utilizes the extremely rapid and intense deposition of energy at the particle surfaces; causes shape deformation and thereby produce inter-particle bonding and keep the compacts homogeneous throughout as well. The high pressure pulse acts only for microsecond offers no opportunity for the grain-growth or formation of undesired phases. The high pressure is accompanied by high temperature which melts the particle surface and is responsible for solid state diffusional bonding of the particles whereas the high cooling rates of the order of $\sim 10^{5} \mathrm{~K} / \mathrm{s}$ does not allow the material to melt ${ }^{[10,11]}$. Therefore, this type of rapid solidification retains the original crystalline and microstructure of the compacts. The basic problem while working with explosive compaction of metals and alloys is the controlled detonation pressure. To avoid rigorous repetition of field trials for optimization of shock wave parameters, a well coupled Computer simulations by using ANSYS software AUTO DYNE-2D in Eulerian mesh has been performed before carrying out the actual experiments.

This paper presents the computer simulation studies and experimental verification of shock consolidated granular copper powder. The crystal structure and the corresponding microstructure before and after shock compaction has been studied and correlated with the theoretical aspects of shock consolidation phenomena. The computational results are in upright agreement with the experimental outcome.

\section{Experimental}

The experimental method involves a cylindrical compaction system in which powder container ampule is surrounded by a Perspex pipe and the space in-between is tapped gently with high energetic explosive. The ampule is made of mild steel to withstand with shape deformation with a conical top and plane bottom plugs. The plugs are fabricated with annular grooves so that during rapid solidification process the material may flow into those grooves and thus making a single conglomerate ${ }^{[12,13]}$. An electric detonator is placed on the top center of the explosive loaded assembly which is further connected to a generator capacitor exploder to initiate the detonation reaction. A pin contactor technique is employed to measure the detonation velocity of the explosive in the reactive media. A series of electrical pins is placed through drilled holes on the bottom half of the assembly at various depths which served to determine the arrival time of shock wave as it passes through these electrical pins. The output of these pins is connected to the digital storage oscilloscope where the electrical signal is converted to the voltage pulses by a pulser and the arrival time of shock wave can be determined. Knowing the arrival time and distance between the pins, detonation velocity can be calculated by the following relation:

$$
P_{C J}=\frac{\rho_{0} D^{2}}{\gamma_{C J}+1}
$$

And the corresponding particle velocity can be calculated by

$$
u_{p}=\frac{D}{\gamma_{C J}+1}
$$

Where, is density of explosive used and is adiabatic exponent of CJ-point with a value of 3 in present case. Upon reaction initiation, a detonation wave on interaction with explosive process a shock wave which traverses down to the explosive column and a rarefaction wave produces a side on pressure thus collectively an axisymmetric shock pressure consolidates the powder material.

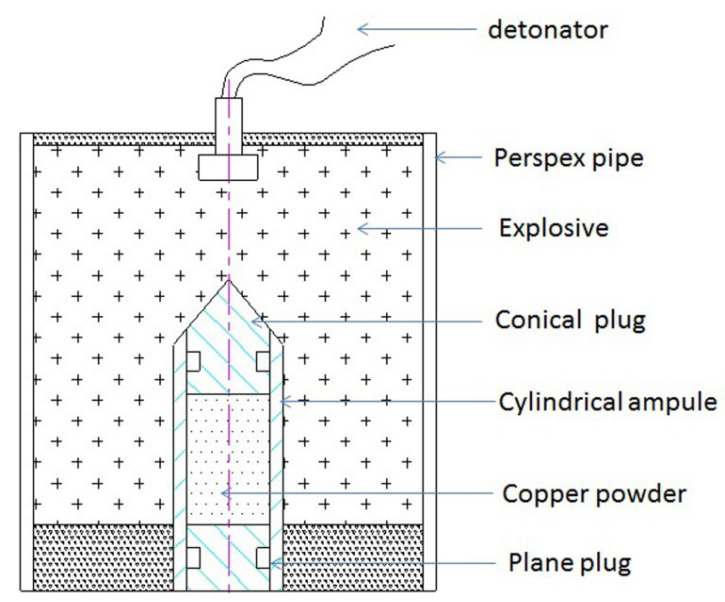

Figure 1. Axisymmetric cylindrical compaction system with explosive in close proximity with $\mathrm{Cu}$. 
The recovered specimen is machined for crystal structure, microstructural features and microhardness. Wide angle X-ray Diffraction using X'PERT X-ray detector with step time of 1.0 s and step size of 0.02 ( $2 \theta$ ) operating at $40 \mathrm{KV}$ over the angle range 30 to $80^{\circ}$. The initial powder morphology was examined by using SEM JEOL JSM operating at $25 \mathrm{kV}$ and a pressure of $10^{-5}$ torr. The microstructural study from the fractured pats of the specimen was observed by FE-SEM at high magnification. The microhardness of the compacted specimen was determined by Lieca microhardness tester with indent load of $50 \mathrm{gf}$ and $100 \mathrm{gf}$ loads. The particle sizes were measured by using small angle laser light scattering method whereas the density of the final product was measured by using nitrogen pycnometry.

The shock parameters have been computed by nonlinear transient numeric simulation using an Eulerian code in AUTODYN 2D workbench. The equation of state for the powder and distended materials is governed by the Mie-Grüneisen relation:

$P-P_{r e f}=\Gamma \rho\left(E-E_{r e f}\right)$

$P_{r e f}=\frac{\rho_{o} c_{o}^{2} \mu(1+\mu)}{[1-(s-1) \mu]^{2}}$

$E_{\text {ref }}=\frac{1}{2} \frac{P_{r e f}}{\rho_{o}}\left(\frac{\mu}{1+\mu}\right)$

$\mu=\frac{\rho}{\rho_{o}}-1$

Where, $\mathrm{P}$ is the Shock -pressure, $\rho_{o}$ is initial tapped density, $\mathrm{s}$ is fitting parameter obtained by the slope of curve (shock velocity-particle velocity curve) and $\Gamma$ is Mie Grüneisen parameter with a value of 2 for $\mathrm{Cu}{ }^{[14,15]}$. The solution is obtained by modeling the consolidation experiment in $2 \mathrm{~d}$ axisymmetric configuration. The explosive has been modeled by assuming that on detonation, the propagating detonation wave transfers its energy to the surrounding material at the reference density of $1.5 \mathrm{~g} / \mathrm{cc}$. The solution of the full set of equations is obtained numerically by using Eulerian space referential. In order to produce infinite boundary conditions, the material flow out and pressure transmission conditions have been applied to the Eulerian space. In order to observe the shock pressure variation with respect to distance from the core, the sensing probes has been placed at the core and also at radial distances of $3 \mathrm{~mm}$ and $5 \mathrm{~mm}$ of the powder compact including the compaction ampoule. For the initiation of detonation, the point detonation has been chosen and applied at the top of the set-up as shown in Figure 2.

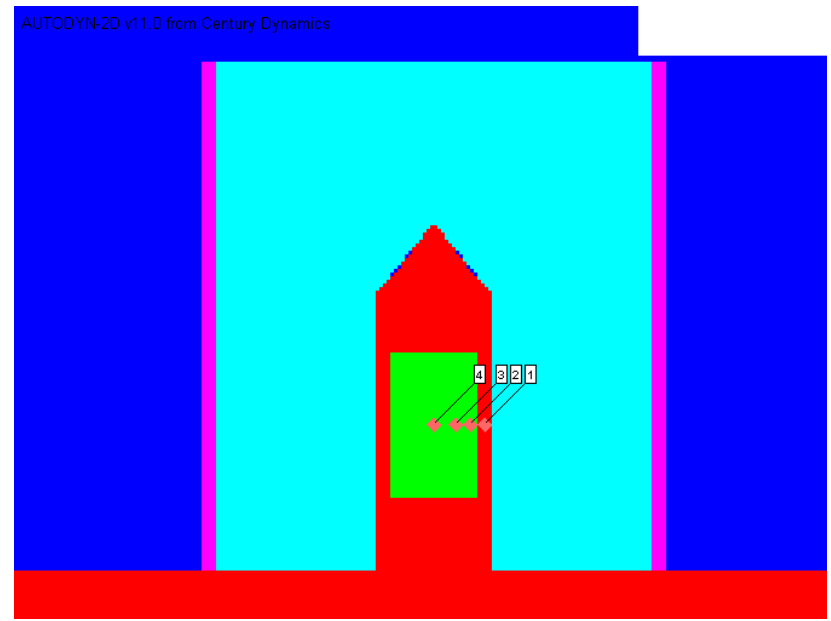

Figure 2. modeling for shock-consolidation set-up with gauge points.

\section{Results and Discussion}

\subsection{Simulated and Experimental Determination of Detonation Velocity}

The shock pressures are predicted at the core and also at radial distances of $3 \mathrm{~mm}$ and $5 \mathrm{~mm}$ of the powder compact including the compaction ampoule. By proper selection of the Eulerian simulation parameters, the modeling of air, copper powder and explosive has been employed to calculate shock pressures with the theoretical values. The granular copper powder, weighing $12.25 \mathrm{~g}$ with average particle size of 22 micron, has been filled manually into ampoule by tapping to a density of $4.6 \mathrm{~g} / \mathrm{cc}$. The filled ampoule is placed centrally inside the outer tube made of aluminum alloy. A plastic explosive, weighing $0.277 \mathrm{Kg}$ has been filled into the annular space between ampoule and outer tube to a density of $1.5 \mathrm{~g} / \mathrm{cc}$.

Figure 3 depicts the simulated detonation pressure profile as the shock wave approaches the gauge points whereas output pulse record obtained by pin contactor method provides arrival time of shock wave as it approaches the electrical pins. The distance at which these pins were inserted into the perspex pipe is known already. Hence, velocity of detonation can be calculated. The experimental average value of detonation velocity is found to be $7.5 \mathrm{~km} / \mathrm{s}$ which correspond to the detonation pressure of the order of $18.38 \mathrm{GPa}$. On the other hand simulated detonation pressure is of the order of $17.1 \mathrm{GPa}$ with a net dispersion of $6.9 \%$.

The shock pressures are predicted at the core of the powder compact including the compaction ampoule. The shock pressure at the core has been calculated as $41.3 \mathrm{GPa}$, wherein $\rho=8.5 \mathrm{~g} / \mathrm{cc}, \mathrm{u}_{\mathrm{s}}=4.744 \mathrm{~km} / \mathrm{s}$ and $\mathrm{u}_{\mathrm{p}}=$

DOI: https://doi.org/10.30564/jmmr.v4i1.3631 


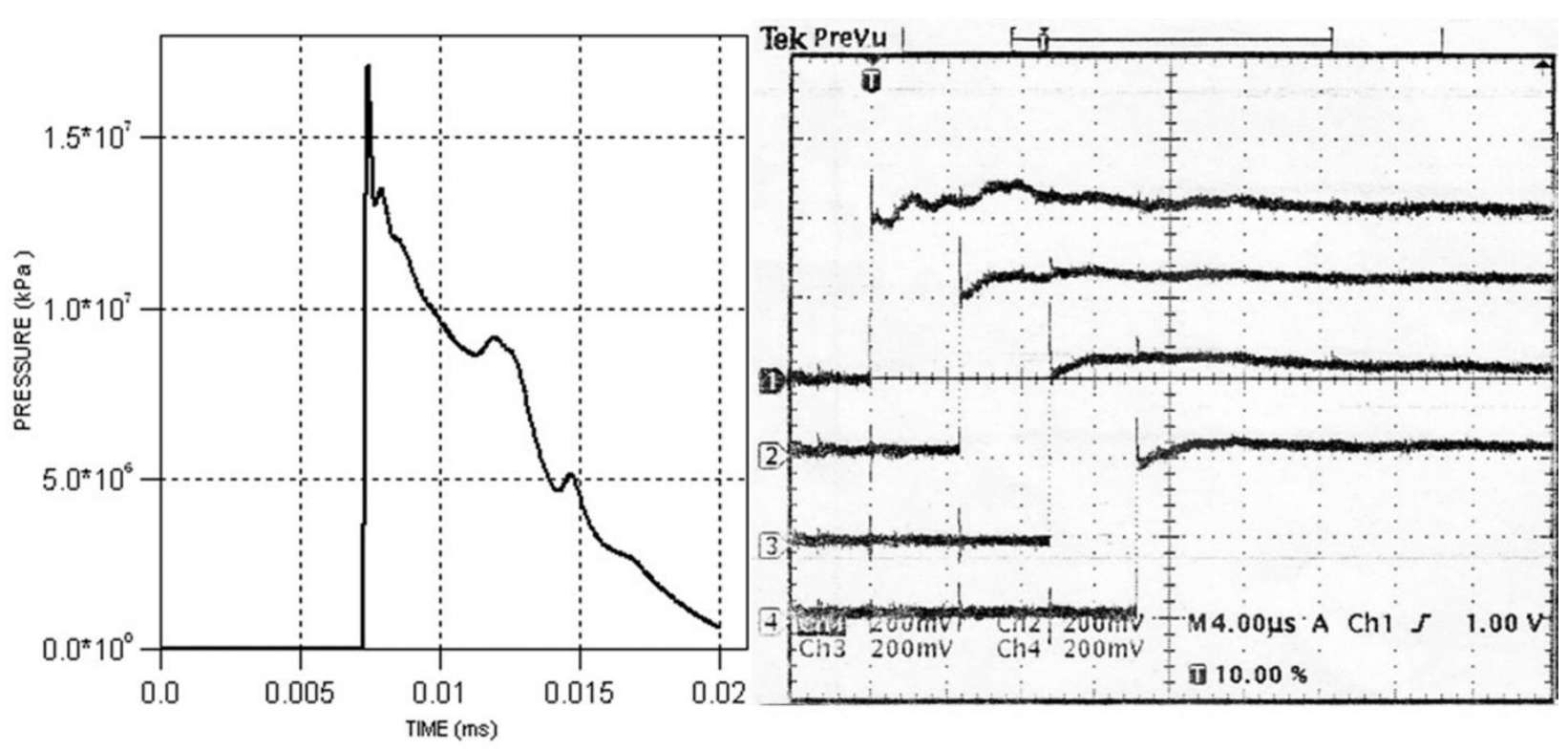

Figure 3. Simulated detonation pressure profile and output pulse record obtained by pin contactor.

$1.024 \mathrm{~km} / \mathrm{s}$. The simulated shock pressure profile at core is shown in Figure4, which stipulates a peak pressure of $38.7 \mathrm{GPa}$. The dispersion between the simulated and theoretically calculated values of peak pressure is $6 \%$.

\subsection{Crystal Phase Determination}

Figure 5 is wide angle $\mathrm{x}$-ray diffraction (WAXD) pattern of the un-shocked initial and shocked specimen. Peak positions clearly be identified and corresponds to FCC structure for both the specimens. No other peak can be detected in the WAXD pattern is a suggestive of absence of undesired phases in the shocked specimen. This means that the compacts have retained their crystalline structure intact. A little noise in the shocked specimen as compared to the un-shocked specimen can be attributed to the partial amorphization which actually is due to the re-solidified melted regions across the interparticle boundaries and is responsible for the solidstate diffusional bonding between the particles. Another specific feature evident from the WAXD pattern is the peak broadening of the shocked specimen which indicates particle size reduction and complements the theoretical considerations. Under the high pressure of the order of $41.3 \mathrm{GPa}$ the particles undergo plastic deformation mechanism which reduces the particle size ${ }^{[16]}$.

\subsection{Microstructural Analysis}

Figure 6 (a) represents initial powder morphology of the granular smooth fine orange-red colored copper particles with fernlike structure. Few small satellite particles can be seen to attach with large particles with a well-defined dendritic structure. The average particle size as suggested by micrographs is observed to be about 30 $\mu \mathrm{m}$ which matches with the average size taken from the laser diffraction based scattering experiment. A guassian distribution of the particles corresponds to avergae mean diameter of $22 \mu \mathrm{m}$ as shown in Figure 6. The fractured morphology of the consolidated specimen taken from the inner core where the pressure was intense, is shown in Figure 6(b). One feature is quite prevalent that the original dendritic structure of the specimen has remained intact and can be observed without any deformation. The particles are joined together via plastic deformations which is in agreement with the theoretical prediction. The interparticle melted regions get re-solidified under high cooling rates of the order of $10^{5} \mathrm{~K} / \mathrm{s}$ thus maintaining the original microstrucutre ${ }^{[17,18]}$. This behaviour is a clear evidence that micro-structural sub-strenghtening has been achieved in this process with specified conditions.

\subsection{Microhardness and Density Measurements}

The microhardness of the consolidated specimen has been tested with diamond indent loads of $0.1 \mathrm{~kg}, 0.05 \mathrm{~kg}$ and $0.025 \mathrm{~kg}$ force. Figure 7 (a) is an optical micrograph of the polished surface of the consolidated copper which appears to have smooth finishing and good uniformity. Figure 7(b) is the optical micrograph with indent loads. It can be discerned from the micrograph that the indent loads have been withheld well by the surface of specimen and no cracking or deformation can be seen. The larger 
Journal of Metallic Material Research | Volume 04 | Issue 01 | April 2021

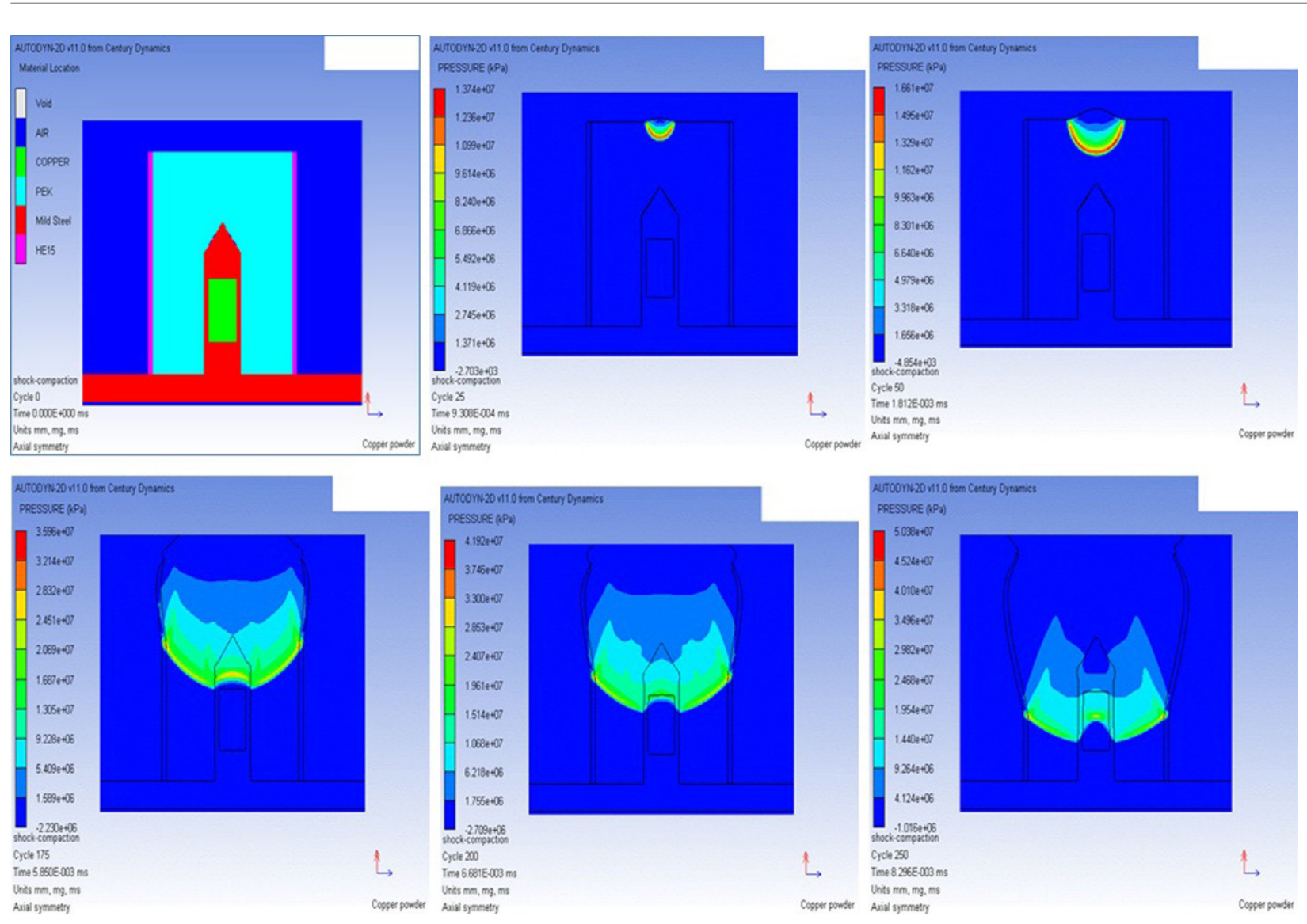

Figure 4. snapshot of the shock wave pressure profile as it traverses down to the explosive consolidation system
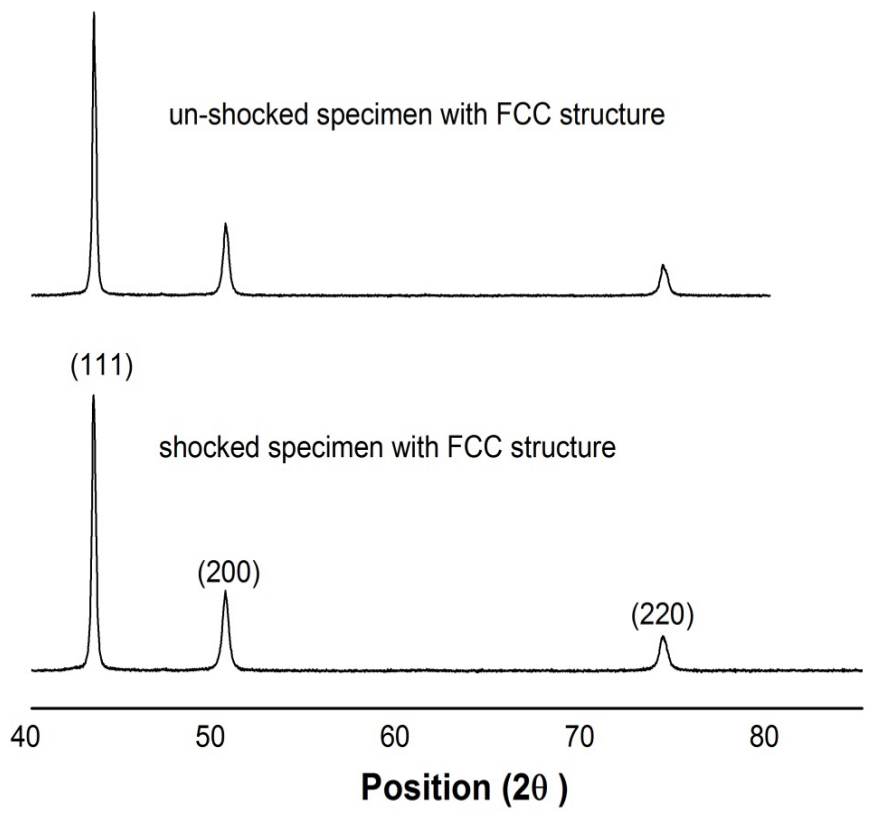

Figure 5. WAXD pattern of un-shocked and shocked granular $\mathrm{Cu}$. 


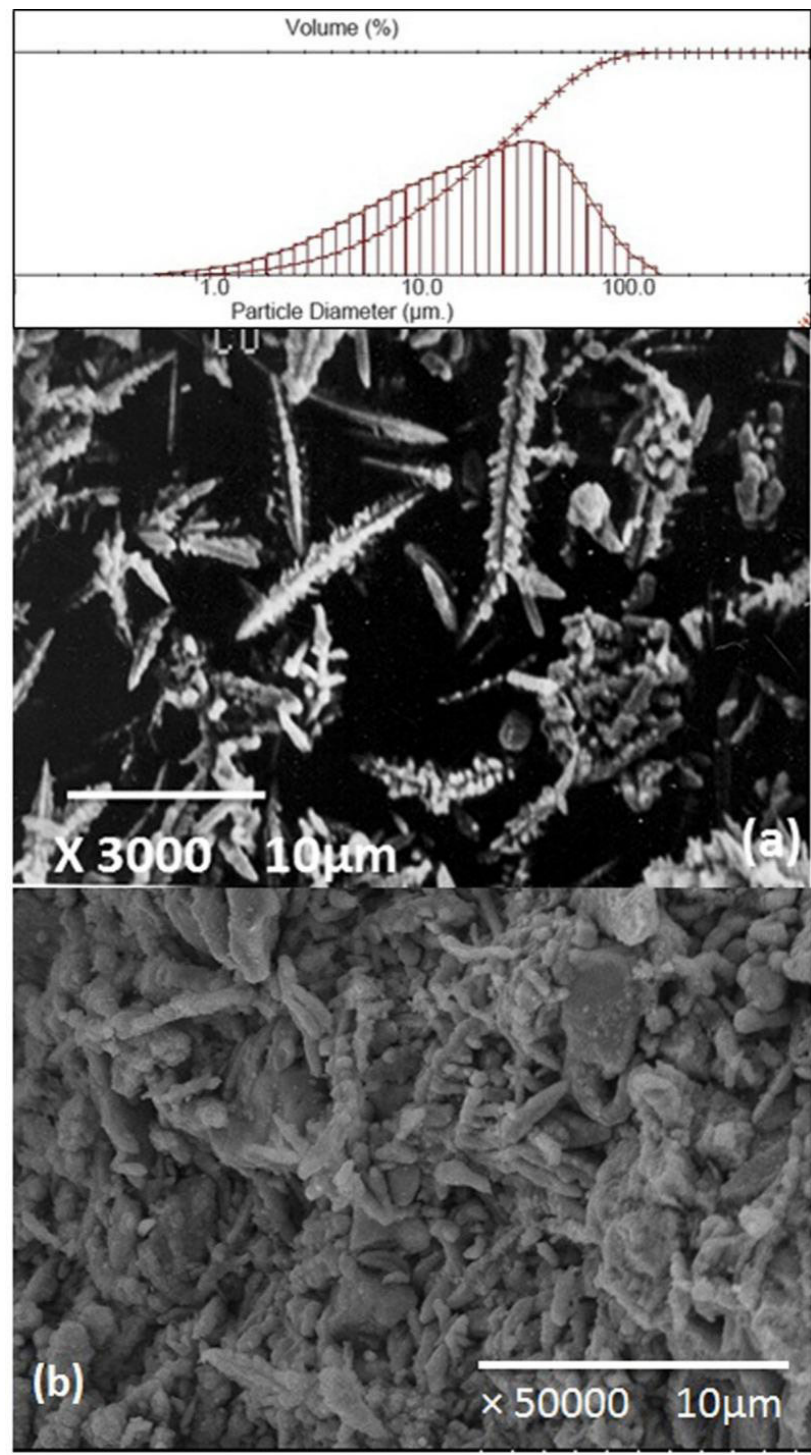

Figure 6. (a) Initial powder morphology showing the dendritic structure; (b) Microstructure from the fractured part of the consolidated specimen showing well bonded structure with intact dendritic structure.

pyramid indent is for $0.1 \mathrm{~kg}$ force whereas the smallest is for $0.025 \mathrm{~kg}$ force. The density of the final product is measured by nitrogen pycnometry corresponds to a value of $99.3 \%$ of the theoretical mean density of $\mathrm{Cu}$.

The observed data with Vicker's microhardness values as per ASTM standard E-92 is shown in Table 1 as follows:

Table 1. Microhardness record obtained under various diamond pyramid indent loads.

\begin{tabular}{cccc}
\hline Average & Maximum & Minimum & Std. Deviation \\
\hline $154 \mathrm{H}_{\mathrm{V}} 0.025$ & $154 \mathrm{H}_{\mathrm{V}} 0.025$ & $154 \mathrm{H}_{\mathrm{V}} 0.025$ & 0.0 \\
$157 \mathrm{H}_{\mathrm{V}} 0.05$ & $159 \mathrm{H}_{\mathrm{V}} 0.05$ & $155 \mathrm{H}_{\mathrm{V}} 0.05$ & 2.19 \\
$136 \mathrm{H}_{\mathrm{V}} 0.1$ & $136 \mathrm{H}_{\mathrm{V}} 0.1$ & $135 \mathrm{H}_{\mathrm{V}} 0.1$ & 0.62 \\
\hline
\end{tabular}

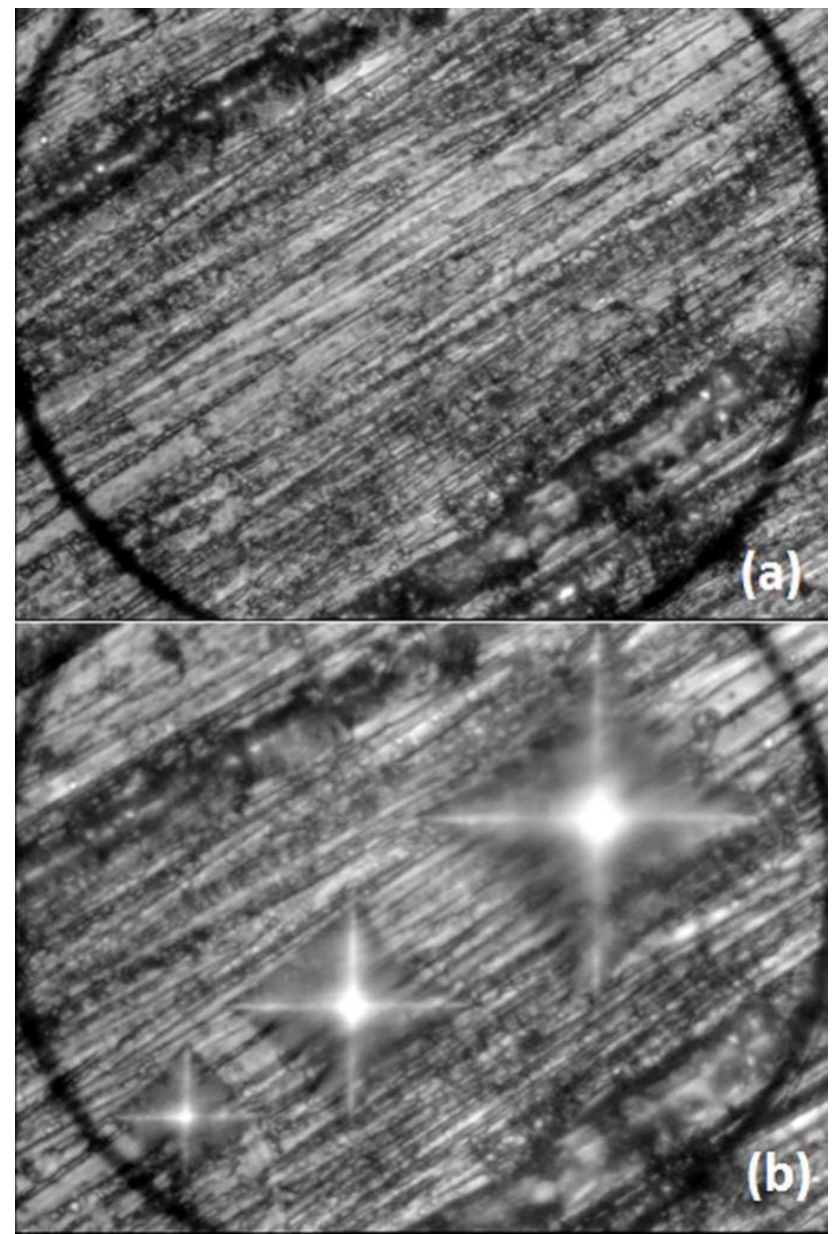

Figure 7. Optical micrographs showing diamond indenters at variable loads.

\section{Conclusions}

A good sub-structural strengthening for granular $\mathrm{Cu}$ has been achieved by using explosively generated shock waves corresponding to a detonation pressure of the order of $18.38 \mathrm{GPa}$ and shock pressure of $41.3 \mathrm{GPa}$. The computational results obtained by simulations in AUTODYN -2d software in Eulerian mesh proved to be an excellent pre-determination of the shock parameters as the results are in close agreement with the experimental outcome with a dispersion of $6 \%$ only. The crystalline structure of the consolidated specimen matches exactly with that of initial specimen without indication of any other phases as revealed by wide angle x-ray diffraction studies. The original dendritic structure remained intact under the shock wave loading without serious melting as conferred by the microstructural studies. An elevated microhardness value of the order of $159 \mathrm{H}_{\mathrm{v}}$ complements the sub-structural strengthening observed by the FESEM. Under the controlled conditions of input parameters the specimen can be consolidated close to the theoretical 
mean density.

\section{Acknowledgements}

The authors desire to acknowledge Defence Research and Development Organization (DRDO), India, for Grantin-aid Project No. ERIP/ER/0703665/M/01/1044. Special thanks go to the University Grants Commission (UGCNew Delhi), India, for providing Research Fellowship No. F.4-1/2006 (BSR)/11-08/2008. Thanks are also due to USIC facility at H.P. University, Shimla and SAIF/ CIL Lab. at Panjab University- Chandigarh and the entire trial team. A distinctive thanks is due to Madan K. Sharma, Yugal K. Yoshi and Rajendra S. Bisht for their necessary assistance and guidance in carrying out the field experiments and numeric simulations.

\section{References}

[1] P.K. Samal, J.W. Newkirk, ASM handbook, Powder metallurgy, 7 (2015).

[2] J.R. Davis, Copper and copper alloys, ASM International (2001).

[3] E. Klar, D. F. Berry, Copper powder metallurgy products, ASM handbook, 2 (1990).

[4] S. Wahyudi, S. Seopryianto, M.Z. Mubarok, Sutarno, IOP Conf. Ser, Mater. Sci. Eng. 395 (2018) 012014.

[5] P.J. James, Fundamental aspects of the consolidation of powders, Powder Met. Int. 4 (1972) 82.

[6] L. Avramovic , V. M. Maksimovic, Z Bascarevic, N. Ignjatovic, M. Bugarin, R.Markovic , N.D. Nikolic , Influence of the shape of copper powder particles on the crystal structure and some decisive characteristics of the metal powders, Metals, 9 (2019) 56.

[7] A.D. Sharma, A.K. Sharma, N. Thakur, Study on the crystal structure and microstructure evolution of shock-processed Titanium powder, J. Met. Mater. Res. 2 (2019) 26-31.

[8] A.D. Sharma, A.K. Sharma, N. Thakur, Effect of explosive contact and non-contact shock processing on structure, microstructure and mechanical character- istics of aluminium, Appl. Phys. A 111 (2013) 783789.

[9] A.D. Sharma, A.K. Sharma, N. Thakur, Shock wave processing of metal powers and their microstructural characterization, AIP Conf. Series: 119 (2011) 1393.

[10] M.A. Meyers, D. J. Benson, E.A. Olevsky, Shock consolidation: microstructurally-based analysis and computational modeling, Acta. Mater. 28 (1999) 2089-2108.

[11] C.T. Wei, E. Vitali, F. Jiang, S.E. Du, D.J. Benson, K.S. Vecchio, N.N. Thadhani. M.A. Meyers, Quasi-static and dynamic response of explosively consolidated metal-aluminum powder mixtures, Acta. Mater. 60 (2012) 1418-1432.

[12] A.D. Sharma, A.K. Sharma, N. Thakur, Crystallographic, microstructural and mechanical characterization of dynamically processed IN718 superalloy, J. Alloys. Comp. 597 (2014) 175-180.

[13] A.D. Sharma, A.K. Sharma, N. Thakur, Crystallographic and morphological characteristics of explosively compacted copper under various detonation velocities, Phil. Mag. 92 (2012) 2108-2116.

[14] M.A. Meyers, Dynamic Behavior of Materials, Wiley, 1994.

[15] M.A. Meyers, D.J. Benson, E. A. Olevsky, Shock consolidation: Microstructurally-based analysis and computational modeling, Acta. Mater. 47 (1999) 2089-2108.

[16] A.D. Sharma, A.K. Sharma, N. Thakur, Effect of explosive contact and non-contact shock processing on structure, microstructure and mechanical characteristics of aluminium, Appl. Phys. A 111 (2013) 783789.

[17] D.G. Morris, Microstructure changes taking place during dynamic compaction of aluminium powders, J. Mater. Sci. 21 (1986) 1111-1117.

[18] A.D. Sharma, A.K. Sharma, N. Thakur, Crystallographic, microstructural and mechanical characterization of dynamically processed EP741NP superalloy, Metall. Mater. Trans. B 47 (2016) 2479-2486. 